\title{
Assessing Genetic Diversity of Wheat Genotypes from Different Origins by SNP Markers
}

\author{
V. SPANIC ${ }^{1 *}$, V. KORZUN ${ }^{2}$ and E. EBMEYER ${ }^{2}$ \\ ${ }^{1}$ Department for Breeding and Genetics of Small Cereal Crops, Agricultural Institute Osijek, \\ Juzno predgradje 17, 31103 Osijek, Croatia \\ ${ }^{2}$ KWS LOCHOW GMBH, Ferdinand von-Lochow-Straße 5, 29303 \\ Bergen, Germany
}

(Received 19 November 2015; Accepted 4 February 2016;

Communicated by A. Börner)

\begin{abstract}
Genetic diversity was investigated in a set of eleven hexaploid wheat genotypes originated from CIMMYT, Turkey in comparison with some modern European mostly originated from KWS wheat breeding program using 24 wheat SNP markers. The lowest and highest genetic dissimilarities were observed between genotypes Opus and LDO 330/06, KWS Salix and LDO 330/06, respectively. Based on cluster analysis, 38 wheat genotypes were grouped in two main clusters. Although the grouping pattern is very origin heterogeneous in each group, the grouping pattern of some genotypes appeared to be associated, to some extent. Principal coordinate analysis ( $\mathrm{PCoA})$ was used as an alternative way of visualizing the genotypic data. The first, second and third principal components explained $17.79 \%, 14.39 \%$ and $12.24 \%$ of the variation, respectively. This study can also be an indicator for breeders to evolve genotypes with diverse genetic background to achieve sustainability in wheat production, to get favorable heterotic combinations in a wheat improvement program.
\end{abstract}

Keywords: genetic diversity, bread wheat (Triticum aestivum L.), SNP markers

\section{Introduction}

Bread wheat (Triticum aestivum L.), a self-pollinating crop, is one of the most important cereal crops in the world in terms of its production and consumption (FAO, 2011). It has one of the largest and most complex genomes among commonly grown agricultural crops. It is allohexaploid ( $2 \mathrm{n}=6 \mathrm{x}=42$, AABBDD) with three homeologous genomes (Sears 1954). The haploid genome is large ( 17 Gb) and investigation has faced difficulties because contains the high proportion of repetitive sequences.

Estimation of genetic diversity can be based on pedigree data, morphological traits or molecular markers. Morphological traits are often influenced by environmental factors. Recently, considerable attention is dedicated to the usage of molecular markers, also as their availability and characterization (Würschum et al. 2013). To date, a variety of molecular techniques have been in usage in wheat such as restriction fragment length polymorphisms (RFLP), random polymorphic amplified DNA (RAPD) and amplified frag-

*Corresponding author; E-mail: valentina.spanic@poljinos.hr 
ment length polymorphisms (AFLP), which have been used successfully for genetic mapping, phylogenetic relationships, comparative genomic studies, and genetic diversity evaluation. However, none of them have been used extensively in breeding programs because they do not meet the requirements for efficient application in marker assisted selection (MAS) (Ren et al. 2013).

Simple sequence repeat (SSR) markers are easy to use, relatively low cost, and high degree of polymorphism is provided by the large number of alleles per locus. At a much higher frequency in the genome occur single nucleotide polymorphism (SNP) markers, which are bi-allelic and their genotyping is automated. They are the most common type of sequence variation in the genome (Rafalski 2002) and can provide the best map resolution. For crop improvement and for the conservation of genetic resources information about genetic diversity and genetic structure is important.

Due to modern breeding, it has been postulated that genetic diversity in wheat has been increasingly narrowed and has suffered an overall reduction with time with pure-line selection. Intensive plant breeding is generally considered to be a practice that leads to reduced genetic diversity (Fu et al. 2006). Narrow genetic diversity also can make problem in breeding for adaptation to biotic and abiotic stresses, so it is necessary to investigate the genetic diversity in wheat germplasm in order to broaden the genetic variation in future wheat breeding (Gorji and Zolnoori 2011). Knowledge of genetic diversity among adapted genotypes or elite breeding materials has a significant impact on the improvement of crop plants and this information has been successfully used for efficient germplasm management and genotype selection for different breeding purposes (Eivazi et al. 2008). The objective of our study was to evaluate the genetic diversity in a wheat collection from different origins using single nucleotide polymorphism (SNP) markers by using competitive allele specific PCR (KASP). This technology has evolved to be a global benchmark technology (Semagn et al. 2014).

\section{Materials and Methods}

\section{Plant material}

Thirty-eight wheat genotypes (eleven obtained from CIMMYT, Turkey, fourteen obtained from KWS, four from other breeding programs from Germany, three from Agricultural Institute Osijek, two from INRA, France, one from China, Romania, Poland and UK) were used to establish the experimental materials for this investigation. In Table 1, the origin and pedigree of tested genotypes are shown.

\section{Molecular analysis of genetic diversity}

In this study, we used 24 SNP markers to investigate relationships among 38 wheat genotypes. For molecular analysis fresh leaves from seedlings were selected randomly from each genotype. After drying in a lyophilizer for a period of 72 hours, they were ground in a laboratory oscillatory mill for 5-10 minutes. After that genomic DNA was extracted and genotyped with 24 SNPs using the KASP method. KASP genotyping assay utilizes a 
Table 1. Origin and pedigree of investigated genotypes

\begin{tabular}{|c|c|c|c|}
\hline No. & $\begin{array}{c}\text { Names or accession } \\
\text { number of the } \\
\text { genotypes }\end{array}$ & Origin & Pedigree \\
\hline 1 & 9807 & CIMMYT, Turkey & $\begin{array}{l}\text { HBK0935W-24/KS84W063-9-34-3-2//Kar192/4/ } \\
\text { Shark/F4105W2.1 }\end{array}$ \\
\hline 2 & 9811 & CIMMYT, Turkey & Alpu/VP5053 (WA\#FM/201/23*2/GS50A) \\
\hline 3 & 9813 & CIMMYT, Turkey & Seri.1B*2/3/Kauz*2/Bow//Kauz/4/Burbot-4/5/Boema \\
\hline 4 & 9815 & CIMMYT, Turkey & PSK/NAC//Sabalan/3/Tam200/Kauz \\
\hline 5 & 9819 & CIMMYT, Turkey & Gansu-1/Mezgit-4 \\
\hline 6 & 9820 & CIMMYT, Turkey & Attila/2*Pastor//Yumai 29 \\
\hline 7 & 9822 & CIMMYT, Turkey & Karl//CTK/VEE/3/F1502W9.01/4/Stephens \\
\hline 8 & 9823 & CIMMYT, Turkey & Seri.1B*2/3/Kauz*2/Bow//Kauz/4/Bagci2002 \\
\hline 9 & 9824 & CIMMYT, Turkey & $\begin{array}{l}\text { Dorade-5/5/YMH/HYS//HYS/TUR3055/3/DGA/4/ } \\
\text { VPM/MOS }\end{array}$ \\
\hline 10 & 9825 & Romania & 06579G1-1 \\
\hline 11 & 9829 & CIMMYT, Turkey & AWD99*5725/FL9547 \\
\hline 12 & 9831, Koreli & INRA, France & \begin{tabular}{|c|} 
CF99075/Caphorn//DI01022 \\
\end{tabular} \\
\hline 13 & 9832, DI09016 & INRA, France & Kareli/Caphorn \\
\hline 14 & 9833 & CIMMYT, Turkey & Attila/2*Pastor//Yumai 29 \\
\hline 15 & Bonanza & Eckendorf, Germany & Türkis/Hermann \\
\hline 16 & Butaro & $\begin{array}{l}\text { Dottenfelder Hof, } \\
\text { Germany }\end{array}$ & - \\
\hline 17 & China-2 & China & - \\
\hline 18 & Dekan & $\begin{array}{l}\text { KWS LOCHOW } \\
\text { GMBH, Germany }\end{array}$ & SB 1/9/83*LP 10990.80/*Greif \\
\hline 19 & Divana & $\begin{array}{l}\text { Agricultural Institute } \\
\text { Osijek, Croatia }\end{array}$ & $\begin{array}{l}\text { Favorit/5/Cirpiz/4/Jang-Kwang/2/Atlas-66/ } \\
\text { Comanche/3/Velvet }\end{array}$ \\
\hline 20 & Golubica & $\begin{array}{l}\text { Agricultural Institute } \\
\text { Osijek, Croatia }\end{array}$ & Slavonija/Gemini \\
\hline 21 & JB Asano & $\begin{array}{l}\text { SaatzuchtBreun, } \\
\text { Germany }\end{array}$ & STRU 2158/Record \\
\hline 22 & Julius & $\begin{array}{l}\text { KWS LOCHOW } \\
\text { GMBH, Germany }\end{array}$ & Asketis/Drifter \\
\hline 23 & KWS Dakota & $\begin{array}{l}\text { KWS LOCHOW } \\
\text { GMBH, Germany }\end{array}$ & 04-28 310528/Tommi/Alceste \\
\hline 24 & KWS Ferrum & $\begin{array}{l}\text { KWS LOCHOW } \\
\text { GMBH, Germany }\end{array}$ & Magnus/Apache \\
\hline 25 & KWS Loft & $\begin{array}{l}\text { KWS LOCHOW } \\
\text { GMBH, Germany }\end{array}$ & Limes/Tulsa//Skalmeje \\
\hline 26 & KWS Magic & $\begin{array}{l}\text { KWS LOCHOW } \\
\text { GMBH, Germany }\end{array}$ & $310010 /$ Cubus \\
\hline
\end{tabular}


Table 1 (cont.)

\begin{tabular}{|c|c|c|c|}
\hline No. & $\begin{array}{c}\text { Names or accession } \\
\text { number of the } \\
\text { genotypes }\end{array}$ & Origin & Pedigree \\
\hline 27 & KWS Montana & $\begin{array}{l}\text { KWS LOCHOW } \\
\text { GMBH, Germany }\end{array}$ & $\mathrm{Kadu} / \mathrm{Cubus} / /$ Privileg \\
\hline 28 & KWS Salix & $\begin{array}{l}\text { KWS LOCHOW } \\
\text { GMBH, Germany }\end{array}$ & Ambition/Global \\
\hline 29 & LDO $329 / 06$ & $\begin{array}{l}\text { Developed in the } \\
\text { research by KWS } \\
\text { LOCHOW GMBH }\end{array}$ & Opus/SW1-91//Opus///Opus///Opus \\
\hline 30 & LDO 330/06 & $\begin{array}{l}\text { Developed in the } \\
\text { research by KWS } \\
\text { LOCHOW GMBH }\end{array}$ & Opus/SW1-91//Opus///Opus///Opus \\
\hline 31 & Macro & KWS UK, UK & Orestis/Lynx//Bandit \\
\hline 32 & Opus & RAGT, UK & Blitz/Fregat \\
\hline 33 & Scirocco & $\begin{array}{l}\text { KWS LOCHOW } \\
\text { GMBH, Germany }\end{array}$ & Eminent/Taifun \\
\hline 34 & Srpanjka & $\begin{array}{l}\text { Agricultural Institute } \\
\text { Osijek, Croatia }\end{array}$ & Osk.4.50-1-77/Zg.2696 \\
\hline 35 & SW1-91 & $\begin{array}{l}\text { Developed in the } \\
\text { research by KWS } \\
\text { LOCHOW GMBH }\end{array}$ & DH-L/Nandu \\
\hline 36 & Taifun & $\begin{array}{l}\text { KWS LOCHOW } \\
\text { GMBH, Germany }\end{array}$ & Naxos/Consens \\
\hline 37 & Tobak & Eckendorf, Germany & Ellvis/Drifter//Koch \\
\hline 38 & Tonacja & $\begin{array}{l}\text { Roslin Strezelce, } \\
\text { Poland }\end{array}$ & Jubilatka/SMH-2182 \\
\hline
\end{tabular}

unique form of competitive allele-specific PCR combined with a novel, homogeneous, fluorescence-based reporting system for the identification and measurement of genetic variation to detect single nucleotide polymorphisms (He et al. 2014).

\section{Statistical analysis}

Clustering analysis was performed based on the UPGMA method, considering the Rogers dissimilarity coefficient available in the software PowerMaker (Liu and Muse 2005). The modified Rogers' distances ( $\mathrm{dw}$ ) were calculated. Relationships among the 38 genotypes were analyzed by applying principal coordinate analysis (PCoA) (Gower 1966) based on the modified Rogers' distances (Wright 1978).

\section{Results}

The 38 genotypes evaluated were divided into two main groups (Fig. 1), using UPGMA dendrogram based on Rogers' dissimilarity (average $=0.68$ ). Results indicated that Tur- 


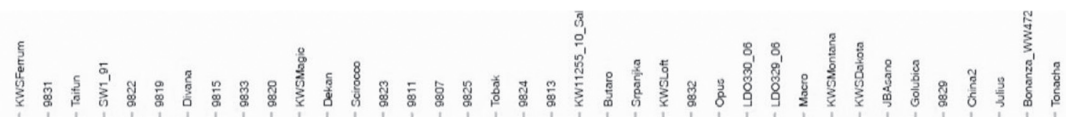

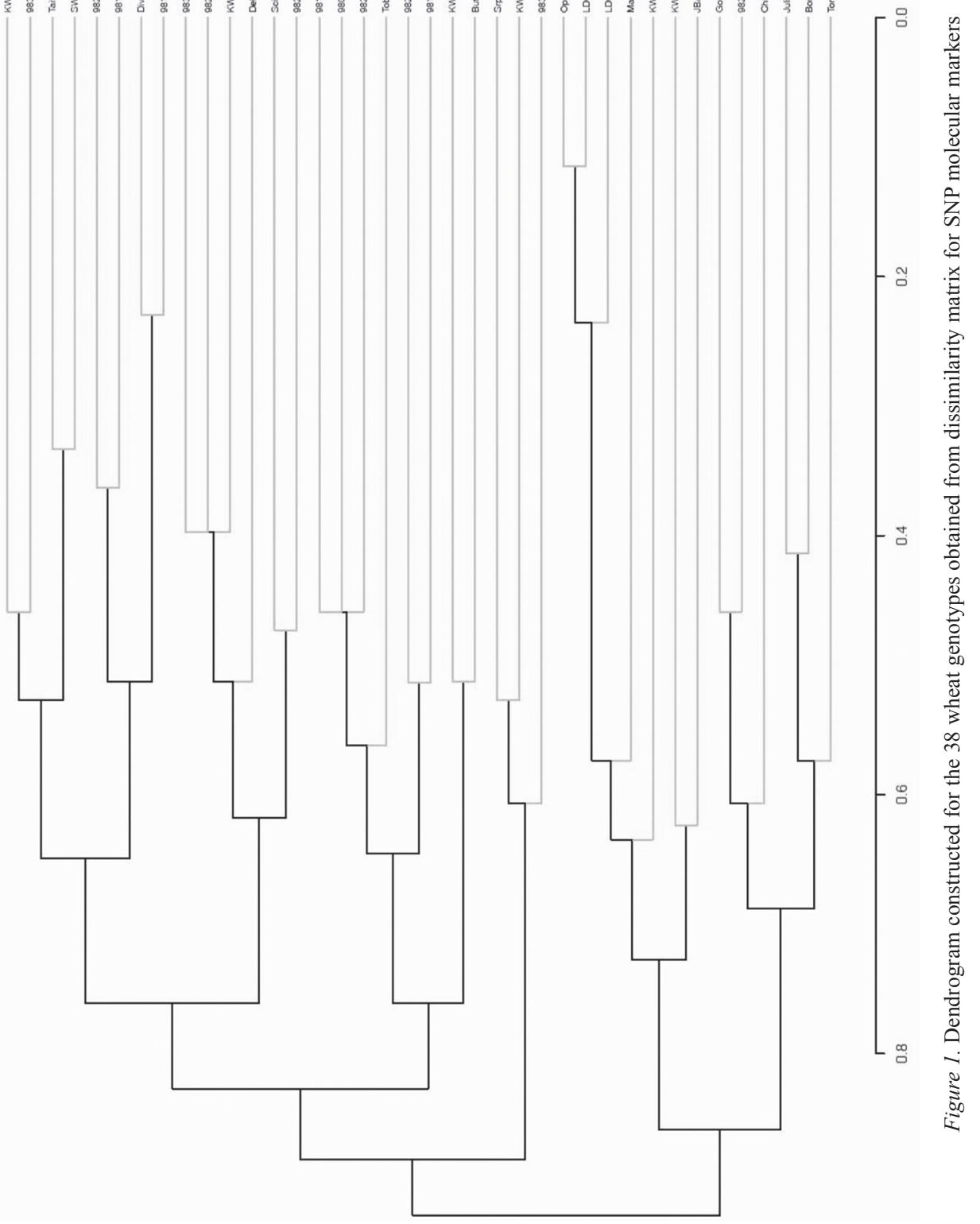


key grown wheat genotypes were grouped mostly in one cluster, with few exceptions from other breeding origins and German material was grouped in the first and second cluster, also with exceptions from other breeding origins. Cluster I included 25 genotypes. In this group ten genotypes originated from Turkey, eight genotypes from KWS LOCHOW GMBH and seven genotypes from others breeding programs. In this group genotypes Divana and 9815 had the lowest genetic dissimilarity. Genotypes Srpanjka, KWS Loft and 9832 stood apart from other subgroups. In second cluster 13 genotypes were grouped, from which six genotypes originated from KWS, one genotype from CIMMYT, Turkey and six genotypes from other breeding programs. The lowest and highest genetic dissimilarities were observed between Opus and LDO 330/06, KWS Salix and LDO 330/06, respectively. The resulting dissimilarity matrix revealed values ranged from 0.12 to 0.92 . Genotypes 9822 and 9819 had dissimilarity coefficient of 0.36 . Genetic dissimilarity between genotypes Divana and 9815 was 0.23 . Genotypes Scirocco and 9823 had dissimilarity coefficient of 0.47. Genotypes 9811,9807 and 9825 had dissimilarity coefficient of 0.46. For genotypes 9824 and 9813, KWS Salix and Butaro coefficient of genetic dissimilarity was 0.52 . Genotypes Opus and LDO 330/06 had genetic dissimilarity of 0.11 . LDO 329/06 had dissimilarity coefficient of 0.24 with Opus and LDO 330/06.

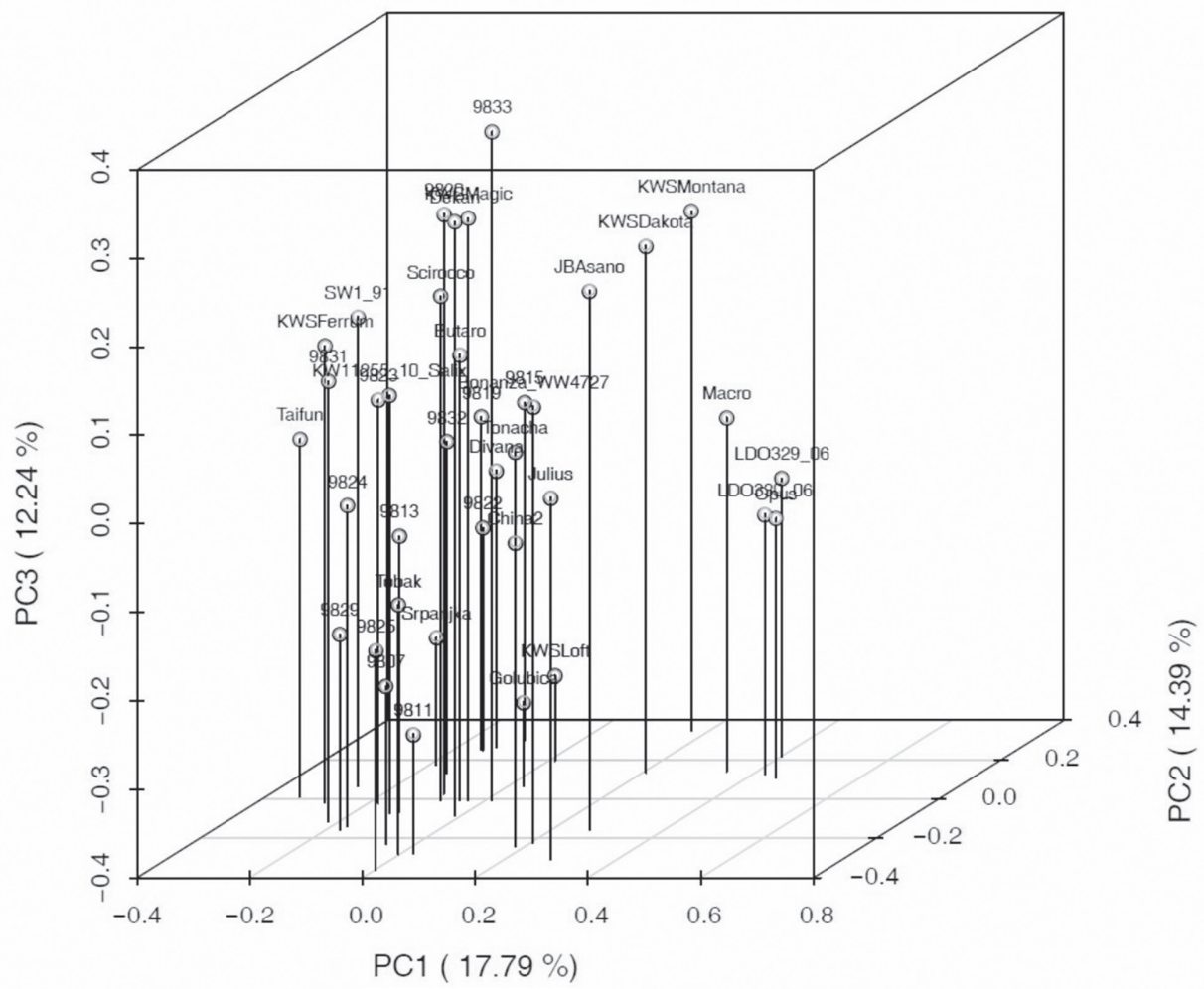

Figure 2. Principal coordinate analysis of 38 hexaploid wheat genotypes in three dimensional plot 
Genotypes Golubica and 9829 had genetic dissimilarity of 0.46 . KWS Julius and KWS Bonanza had also lower dissimilarity (0.41). Other genotypes had genetic dissimilarity more than 0.50, such as Srpanjka and KWS Loft, and these two with 9832, KWS Macro and KWS Montana with Opus, KWS Dakota and JB Asano, China 2 with Golubica and 9829, Tonacja with KWS Julius and Bonanza.

Principal coordinate analysis (PCoA) was used as an alternative way of visualizing the genotype data (Fig. 2). The first, second and third principal components explained $17.79 \%, 14.39 \%$ and $12.24 \%$ of the variation, respectively. Principal coordinate analysis revealed a clear grouping among some CIMMYT genotypes (9829, 9825, 9807 and 9811). Genotype 9833 stood out from all other genotypes. In principal coordinate analysis some of genotypes grouped according to the country of origin. Three German genotypes (LDO 329/06, LDO 330/06 and Opus) formed a distinct cluster. Genotypes KWS Montana and KWS Dakota together with JB Asano were also separated. A close relationship was revealed between genotypes KWS Magic, Dekan and 9826.

\section{Discussion}

We investigated the genetic dissimilarity in the panel of 38 wheat genotypes by cluster analysis and principal coordinate analysis (PCoA) based on the modified Rogers' distances between the individuals. Since most of the analyzed germplasm is derived from CIMMYT, Turkey or KWS LOCHOW GMBH, Germany, a higher similarity between genotypes inside of these two groups was expected. Clustering of the genotypes is in accordance with research of Huang et al. (2000) where they concluded that all genotypes that originating from same geographic region did not cluster in the same group. Although in our study the grouping pattern is very origin heterogeneous in each group, the grouping pattern of some genotypes appeared to be associated, to some extent. Genotypes Opus and LDO 330/06 were genetically the closest, which was expected, because genotype LDO 330/06 derived from Opus. Values in dissimilarity matrix are similar with the work of Drikvand et al. (2013), who calculated according to similarity matrix, that genetic distance value ranged from 0.17 to 0.88 .

Low genetic dissimilarity was obtained between genotypes KWS Ferrum and 9831 (Koreli) because KWS Ferrum has parents Magnus and Apache (French wheat variety). Genotype Koreli is the product of joint research by the INRA "small grain crops" group, breed by INRA research units from Clermont-Ferrand (France). Genotypes KWS Ferrum and Koreli have some common alleles because in their deep pedigrees Cappele-Desprez was used. Genotypes 9822 and 9819 were close in genetic structure, although their pedigree does not match, they are originating from the same place (CIMMYT, Turkey). Genotypes Divana and 9815 have in common in deep pedigree Bezostaya-1. Genotypes 9833 , 9820 and KWS Magic also share a low genetic dissimilarity. This was not unusual for 9833 and 9820 which are sister lines. KWS Magic has in deep pedigree genotypes Mentana (Kenya-58/Frontana) which also could be found in Attila and Pastor, which are one of the parents of 9833 and 9820 . We do not know exactly where the linkage is in pedigree of genotypes Scirocco and 9823. Lower dissimilarity coefficient was not unu- 
sual for genotypes 9811 and 9807 because those came from the same origin (CIMMYT, Turkey). But genotype 9825 came from Romania, which often used the same material in crossing as Turkey and surrounding countries. Very close were genotypes Opus and LDO $330 / 06$, which was expected because LDO 330/06 is a direct progeny of Opus. LDO $329 / 06$ also was originated from the crosses with Opus. Some genotypes in far pedigree of these KWS Julius and KWS Bonanza are the same (Heines-VII and Hybride-Du-Joncquois).

The distribution of the genotypes can be shown more clearly on three dimensions analysis than in the dendrogram (Abdellatid and AbouZeid 2011). According to Pandey et al. (2015) the results of these two methods, cluster analysis and principle coordinate analysis were comparable, which we also can conclude in our study.

This number of SNP markers need to be larger due to the huge genome of wheat, which also was concluded in previous investigations (Song et al. 2005). But anyway cluster grouping gave close matches with some pedigrees and distribution of the genotypes based on the origin. Some authors such as Prasad et al. (2009) had also the similar conclusions. This paper confirmed the hypothesis that the relationship of parents placed genotypes into the same groups on the basis of common alleles. This investigation about information on genetic diversity is helpful for developing appropriate science-based strategies for wheat breeding (Landjeva et al. 2006) and it can be a good tool of selecting genotypes in breeding programs. Diverse genetic base may also resist the spread of diseases (Zhu et al. 2000) in approved genotypes.

Most of the wheat genotypes used in the present study derived from CIMMYT or KWS material. CIMMYT genotypes often have common ancestors in their pedigrees, such as Pastor, Attila and Kauz. Some genotypes do not differ greatly on the loci for which amplification was observed. This can be, probably due to the common parentage, although CIMMYT strategy in other nurseries has been to utilize germplasm sources that are as diverse as possible for disease resistance and that could be adaptable for different environments.

It was expected to find genetic variability in investigated genotypes from different origins. Newly developed single nucleotide polymorphism (SNP) markers are effective in detecting genetic diversity (Ren et al. 2013), but in some cases larger number of markers need to be used due to large genome of wheat. If no pedigree information is available the breeder may use the molecular marker data for selecting the parents/lines for crossing. This study can also be an indicator for breeders to evolve genotypes with diverse genetic background to achieve sustainability in wheat production, to get favorable heterotic combinations in a wheat improvement program and to meet the diversified goals of wheat breeding for increasing yield and stability, good quality, pest and disease resistance.

\section{Acknowledgements}

We acknowledge KWS-Borlaug fellowship for this study and KWS LOCHOW GMBH, Germany for supporting this work. 


\section{References}

Abdellatif, K.F., AbouZeid, H.M. 2011. Assessment of genetic diversity of Mediterranean bread wheat using Randomly Amplified Polymorphic DNA (RAPD) markers. J. of Genetic Engineering and Biotechnol. 9:157-163.

Drikvand, R., Bihamta, M.R., Najafian, G., Ebrahimi, A. 2013. Investigation of genetic diversity among bread wheat cultivars (Triticum aestivum L.) using SSR markers. J. Agric. Sci. 5:122-129.

Eivazi, A.R., Naghavi, M.R., Hajheidari, M., Pirseyedi, S.M., Ghaffari, M.R., Mohammadi, S.A., Majidi, I., Salekdeh, G.H., Mardi, M. 2008. Assessing wheat (Triticum aestivum L.) genetic diversity using quality traits, amplified fragment length polymorphisms, simple sequence repeats and proteome analysis. Ann. Appl. Biol. 152:81-91.

FAO 2011. Food and agricultural commodities production. http://faostat.fao.org/site/339/default.aspx.

Fu, Y.B., Peterson, G.W., Yu, J.K., Gao, L., Jia, J., Richards, K.W. 2006. Impact of plant breeding on genetic diversity of the Canadian hard red spring wheat germplasm as revealed by ESTderived SSR markers. Theor. Appl. Genet. 112:1239-1247.

Gorji, A.H., Zolnoori, M. 2011. Genetic diversity in hexaploid wheat genotypes using microsatellite markers. Asian J. of Biotechnol. 3:368-377.

Gower, J.C. 1966. Some distance properties of latent root and vector methods used in multivariate analysis. Biometrika 53:325-338.

He, C., Holmes, J., Anthony, J. 2014. SNP genotyping: the KASP assay. Methods Mol. Biol. 1145:75-86.

Huang, X.Q., Hsam, S.L.K., Zeller, F.J., Wenzel, G., Mohler, V. 2000. Molecular mapping of wheat powdery mildew resistance gene Pm24 and marker validation for molecular bredding. Theor. Appl. Genet. 101:407414.

Landjeva, S., Korzun, V., Ganeva, G. 2006. Evaluation of genetic diversity among Bulgarian winter wheat (Triticum aestivum L.) varieties during the period 1925-2003 using microsatellites. Genet. Resour. Crop Evol. 53:1605-1614.

Liu, K., Muse, S.V. 2005. Powermarker: An integrated analysis environment for genetic marker analysis. Bioinformatics 21:2128-2129.

Pandey, A., Khan, M.K., Thomas, G., Hakki, E.E., Kayis, S.A., Hamurcu, M., Gezgin, S., Topal, A., Akkaya, M.S. 2015. Estimation of Indian and Turkish hexaploid wheat population structure employing molecular markers. Not. Bot. Horti. Agrobo. 43:70-78.

Prasad, B., Babar, M.A., Xu, X.Y., Bai, G.H., Klatt, A.R. 2009. Genetic diversity in the U.S. hard red winter wheat cultivars as revealed by microsatellite markers. Crop and Pasture Sci. 60:16-24.

Rafalski, A. 2002. Applications of single nucleotide polymorphisms in crop genetics. Curr. Opin. Plant Biol. 5:94-100.

Ren, J., Sun, D., Chen, L., You, F.M., Wang, J., Peng, Y., Nevo, E., Sun, D., Luo, M.C., Peng, J. 2013. Genetic diversity revealed by single nucleotide polymorphism markers in a worldwide germplasm collection of durum wheat. Int. J. Mol. Sci. 14:7061-7088.

Sears, E.R. 1954. The aneuploids of common wheat. Bull. 572. University of Missouri Agricultural. Columbia, SC, USA.

Semagn, K., Babu, R., Hearne, S., Olsen, M. 2014. Single nucleotide polymorphism genotyping using Kompetitive Allele Specific PCR (KASP): Overview of the technology and its application in crop improvement. Mol. Breed. 33:1-14.

Song, Q.J., Shi, J.R., Singh, S., Fickus, E.W., Costa, J.M., Lewis, J., Gill, B.S., Ward, R., Cregan, P.B. 2005. Development and mapping of microsatellite (SSR) markers in wheat. Theor. Appl. Genet. 110:550-556.

Wright, S. 1978. Evolution and Genetics of Populations, Variability within and among Natural Populations, 4th edn. The University of Chicago Press. Chicago, USA.

Würschum, T., Langer, S.M., Longin, C.F.H., Korzun, V., Akhunov, E., Ebmeyer, E., Schachschneider, R., Schacht, J., Kazman, E., Reif, J.C. 2013. Population structure, genetic diversity and linkage disequilibrium in elite winter wheat assessed with SNP and SSR markers. Theor. Appl. Genet. 126:1477-1486.

Zhu, Y., Chen, H., Fan, J., Wang, Y., Li, Y., Chen, J., Fan, J.X., Yang, S., Hu, L., Leung, H., Mew, T.W., Teng, P.S., Wang, Z., Mundt, C.C. 2000. Genetic diversity and disease control in rice. Nature 406:718-722. 